\title{
HEMANGIOMA CAVERNOSO HEPÁTICO
}

\section{LIVER CAVERNOUS HEMAGIOMA}

\author{
Mara Giménez Isasi ${ }^{(1)}$; Domingo Javier Aguilera Maidana ${ }^{(2)}$; \\ Alma Liliana Masi Miranda, Giselle Semidei Dalles ${ }^{(3)}$
}

\section{RESUMEN}

Los hemangiomas forman parte de los tumores benignos más frecuentes en el hígado. Suelen ser asintomáticos y raramente se complican salvo que sean de un tamaño importante. El dolor suele ser el síntoma más común asociado al mismo. La TC suele ser el método auxiliar más empleado. La exéresis quirúrgica está indicada en los casos sintomáticos. Presentamos el caso de una mujer de 60 años que acudió por dolor abdominal de 3 semanas. Se constató en sus estudios auxiliares una masa heterogénea en vecindad con el hígado, páncreas y colon ascendente de $66 \times 32 \mathrm{~mm}$. Se decidió conducta quirúrgica por vía laparoscópica sin complicaciones. El retorno de la anatomía patológica informa hemangioma cavernoso hepático.

Palabras Clave: hemangioma cavernoso, hígado, laparoscopía.

\section{SUMMARY}

Hemangiomas are part of the most common benign tumors in the liver. They are usually asymptomatic and rarely complicate unless they are of an important size. Pain is usually the most common symptom associated with it. CT is usually the most used auxiliary method. Surgical exeresis is indicated in symptomatic cases. We present the case of a 60 -year-old woman who presented with abdominal pain for 3 weeks. A heterogeneous mass in proximity to the liver, pancreas and ascending colon of $66 \times 32 \mathrm{~mm}$ was found in their auxiliary studies. Laparoscopic surgical procedure was decided without complications. The return of the pathological anatomy informs hepatic cavernous hemangioma.

Keywords: cavernous hemangioma, liver, laparoscopy.

\section{INTRODUCCIÓN}

Un hemangioma cavernoso se puede hallar incluso en el 5\% de la población adulta. Por lo general son asintomáticos, pudiendo permanecer estables a lo largo del tiempo; con más razón los pequeños. Los mayores a $4 \mathrm{~cm}$ y particularmente los mayores a $10 \mathrm{~cm}$ pueden llegar a ser sintomáticos. La rotura o la hemorragia son eventualidades posibles, aunque suele ser muy rara su aparición al menos de forma espontánea fuera de punciones, traumatismos etc. ${ }^{(1)}$

Hoy en día es más frecuente el diagnóstico de hemangiomas hepáticos en la práctica médica por el uso amplio de métodos avanzados de diagnóstico por imágenes como la tomografía y la resonancia magnética. ${ }^{(2)}$

Los hemangiomas de hecho son los tumores benignos más frecuentes, y los cavernosos a veces pueden llegar a ser de gran tamaño y exofíticos que eventualmente serán tratados cuando producen síntomas. En estos casos, el tratamiento de elección es la remoción quirúrgica. Otras opciones disponibles son la embolización arterial selectiva, ablación por radiofrecuencia ya sea percutánea o laparoscópica. ${ }^{(3)}$

El hemangioma cavernoso junto con los adenomas y la hiperplasia nodular focal se constituyen en la mayor parte de los tumores benignos hepáticos y su frecuencia puede verse relacionado con estimulación hormonal o estrogénica. ${ }^{(4)}$

\section{CASO CLÍNICO}

Presentamos el caso de una paciente femenina de 60 años que acude por dolor abdominal localizado en hipocondrio derecho y en epigastrio de 3 meses de evolución, sordo, de insidioso inicio que con el correr de los días se acompaña de nauseas post prandiales lo cual motivó su consulta ambulatoria. Al examen físico no se hallan datos de valor. Laboratorialmente todos los parámetros en rango. Se solicita ecografía abdominal que describe LOES sólida, límites bien definidos, ecoestructura inhomogénea, visualizada entre la vesícula y el páncreas, de 66 x 54 $\mathrm{mm}$. Ante ese hallazgo se solicita TC contrastada que describe una imagen subyacente al ángulo hepático del colon, anterior al colon ascendente y adyacente a las asas delgadas compatible con una masa ovalada, heterodensa, no produce efecto de masa significativo sobre los órganos vecinos. Presenta pedículo sólido que se dirige a la región subhepática y planos musculares de la pared abdominal. Mide 66 × $32 \mathrm{~mm}$ no pudiendo descartarse dependencia con asas delgadas pudiendo ser un GIST. Se solicitan EDA y colonoscopía las cuales retornan sin alteraciones

Hospital Central, Instituto de Previsión Social, Servicio de Cirugía General. Paraguay

1. Cirujano de Planta

2. Cirujano de Planta

3. Residentes de 3er. Año.

Autor Correspondiente: Dr. Domingo Aguilera: djaguile@ips.gov.py

Recibido: 14-08-2018 - Aceptado: 16-09-2018 


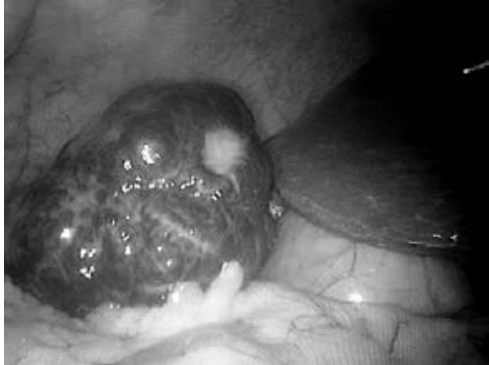

Fig. 1: Tumoración en relación con hígado y ángulo hepático colónico.

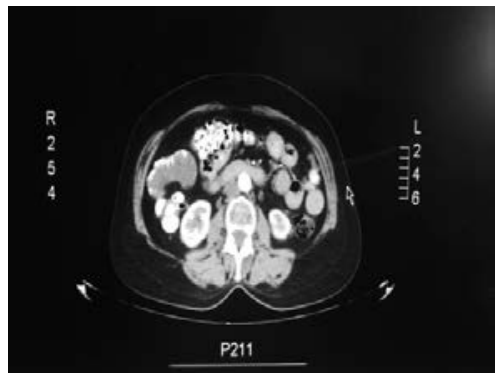

Fig. 2: TC donde se observa tumoración heterogénea con densidad marcada en proyección descrita.

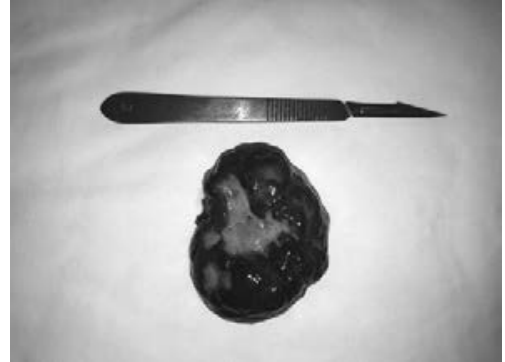

Fig. 3: Pieza quirúrgica resecada. anatómicas en los órganos estudiados.

Ante esos hallazgos se decide conducta quirúrgica. Se accede al abdomen por vía laparoscópica. Se utilizan 3 trócares (12 $\mathrm{mm}$ umbilical, $10 \mathrm{~mm}$ epigastrio y $5 \mathrm{~mm}$ en flanco derecho). Se constata tumoración de aproximadamente $7 \times 5 \mathrm{~cm}$ adherido al borde anterior del hígado entre segmento IV y $\mathrm{V}$ del hígado. Pediculado y sin adherencias a otros órganos. Se procede a liberación y sección de pedículo, hemostasia con clips. Se extrae pieza quirúrgica por ampliación de incisión umbilical. Se da por concluido el acto sin complicaciones. La paciente evolución sin complicaciones siendo dada de alta a las 24 horas del procedimiento. El retorno de anatomía patológica informó hemangioma cavernoso, con remanentes de tejido hepático en la periférica sin rastros de proceso neoplásico maligno.

\section{DISCUSIÓN}

Con el advenimiento de métodos auxiliares más avanzados aumentó notablemente el diagnóstico de estos tumores. La mayoría de ellos son asintomáticos y pequeños. Los mayores a $5 \mathrm{~cm}$ por lo general son los que ocasionan síntomas y son pasibles de tratamiento. El dolor es el síntoma más frecuente. Le sigue en frecuencia los síntomas compresivos cuando son de un tamaño importante. Por lo general los marcadores de funcionalidad hepática no se alteran. La ecografía y la TC contrastada suelen ser muy útiles para tener una aproximación diagnóstica muy precisa. La mayoría solo requiere control médico y seguimiento imagenológico, aunque aquellos sintomáticos podrán ser resecados (dolor sostenido, refractario y que no pueda ser justificado por otra causa). Decidido el tratamiento el procedimiento más seguro es la enucleación quirúrgica. En este caso, por ejemplo, la presencia de un pedículo libre facilitó la exéresis sin riesgo de hemorragia. La embolización y otros procedimientos percutáneos son alternativas, aunque menos efectivas.

\section{REFERENCIAS}

1) Martín L, Rodríguez C, Correro F. (2001). Tumores hepáticos benignos. Tratamiento de las enfermedades hepáticas y biliares. Madrid: ELBA $S A, 2001 ; 239-45$.

2) Benavides C, Garcia C, Rubilar P, Covacevich S, Perales C, Ricarte F, Stock R. (2006). Hemangiomas hepáticos. Revista chilena de cirugía 2006;

58(3), 194-8.

3) San Juan LB. (2006). Hemangioma cavernoso hepático. Revista chilena de cirugía 2006 58(3): 173-4.

4) Mondragón-Sánchez RJ, Oñate-Ocaña LF, Ruiz-Molina JM, Bernal-Maldonado R, Garduño-López AL \& Meneses-García A. Belard O. Cirugía en tumores hepáticos benignos. Cirugía y Cirujanos 2001; 69(3), 123-7. 